\title{
Ensuring Mobility-Supporting Environments for an Aging Population: Critical Actors and Collaborations
}

\author{
Chris S. Kochtitzky, ${ }^{1}$ Amy L. Freeland, ${ }^{1}$ and Irene H. Yen ${ }^{2}$ \\ ${ }^{1}$ Division of Emergency and Environmental Health Services, Centers for Disease Control and Prevention, Atlanta, GA 30341, USA \\ ${ }^{2}$ Department of Medicine, University of California, San Francisco, CA 94143, USA
}

Correspondence should be addressed to Chris S. Kochtitzky, csk3@cdc.gov

Received 28 January 2011; Accepted 21 April 2011

Academic Editor: Steven Hooker

Copyright ( 92011 Chris S. Kochtitzky et al. This is an open access article distributed under the Creative Commons Attribution License, which permits unrestricted use, distribution, and reproduction in any medium, provided the original work is properly cited.

\begin{abstract}
Successful aging takes on an array of attributes, including optimal health and community participation. Research indicates that (1) persons with disabilities, including age-related disabilities, report frequent barriers to community participation, including unsuitable building design (43\%), transportation (32\%), and sidewalks/curbs (31\%), and (2) many seniors report an inability to cross roads safely near their homes. This paper attempts to define mobility-related elements that contribute to optimal health and quality of life, within the context of successful aging. It then examines the impacts of community design on individual mobility, delving into which traditional and nontraditional actors-including architects, urban planners, transportation engineers, occupational therapists, and housing authorities_-play critical roles in ensuring that community environments serve as facilitators (rather than barriers) to mobility. As America ages, mobility challenges for seniors will only increase unless both traditional aging specialists and many nontraditional actors make a concerted effort to address the challenges.
\end{abstract}

\section{Introduction}

The elderly population in the United States has grown from 3 million in 1900 to 39 million in 2008, with a projected growth to almost 90 million by 2050 [1]. Older age has been associated with increased prevalence of chronic diseases [2] and sensory impairments [3]; changes in cognitive processing time [4]; alterations in balance and stamina [5]; increases in falls, fall-related injuries, and death $[5,6]$. Mobility can mitigate some of the negative health consequences of aging and promote social interactions critical to aging successfully; therefore, it is essential to create environments that encourage safe mobility.

Unfortunately, current research indicates that many older Americans live in communities that hinder rather than facilitate safe mobility. Analysis of data from the Centers for Disease Control and Prevention's (CDC's) 2002 National Health Interview Survey indicates that the largest proportion of persons with disabilities, including age related, reported that their most frequent barriers to community participation included unsuitable building design (43\%), transportation
(32\%), and sidewalks/curbs (31\%) [7]. Similarly, a recent AARP study found that between $40 \%$ and $50 \%$ of seniors reported inadequate sidewalks in their neighborhoods and an inability to cross main roads safely near home [8].

Beginning in 2011, 10,000 people will turn 65 every day, and this rate of achieving senior status will continue for 20 years [9]. Moreover, physical activity rates and community engagement level off or decline with increasing agepotentially bringing on declines in health [1]. These patterns could have a significant impact on healthcare and long-term care in the future, since the use of formal and informal health-related services is strongly correlated to increasing age [10]. If we as a society are to respond successfully to these implications, as well as others, we must ensure that the aging population remains healthy, vital, and engaged in their communities as long as possible.

CDC's healthy aging research network (HAN) defines healthy aging as "the development and maintenance of optimal physical, mental and social wellbeing and function in older adults. It is most likely to be achieved when physical environments and communities are safe, and support 
the adoption and maintenance by individuals of attitudes and behaviors known to promote health and well-being; and by the effective use of health services and community programs to prevent or minimize the impact of acute and chronic disease on function" [11]. These statements indicate that in order to maintain optimal health during aging, an individual must be able safely to take advantage of health-promoting behaviors such as physical activity and social interaction, and the individual must be able to access health-promoting resources such as nutritional food, clinical preventive services, and other medical care. Exercising such behaviors and gaining access to such resources is difficult, if not impossible, if an individual's mobility is seriously impaired.

Avoiding mobility impairment during aging is not necessarily something that an individual can accomplish alone, however. The World Health Organization's International Classification of Functioning, Disability, and Health (ICF) defines disability, including such functional limitations as mobility impairment, as an outcome of interactions between health conditions (diseases, disorders, and injuries); contextual factors-such external environmental factors as architectural characteristics, legal and social structures, and so forth; internal personal factors, including age, coping styles, and other factors that influence how disability is individually experienced [12].

The purpose of this paper is to describe a model of the different levels at which the physical environment can influence mobility and to list some of the key individuals or professions that can be most effective in helping to create livable communities that promote optimal mobility throughout the lifespan.

\section{Methodology}

We searched the HAN Database of Environmental and Policy Change Resources [13] and the CDC Healthy Community Design Initiative's resource list [14] to identify a framework on which to base our analyses of key social and environmental elements related to mobility and successful aging. We also did so to identify key fields that are crucial in creating supportive environmental changes. Using the previously referenced definitions and the HAN social ecological model of healthy aging, we examined the physical environments within which mobility occurs (or is constrained) at each of the levels beyond the individual-interpersonal, institutional, community, and public policy. We then listed some of the main actors responsible for mobility-impacting decisions at each level and described the responsibilities and potential actions these individuals/groups could assume and take to ensure optimal mobility for older adults.

2.1. The Model. HAN created the social ecological model of healthy aging (see Figure 1) [15] by merging two separate but related models to reflect the interplay of individualand community-level factors related to successful aging. This model considers the behavioral impact and connections between people and their environments. For this

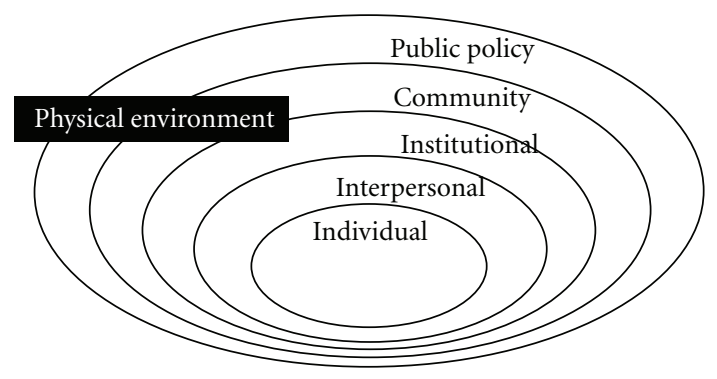

Figure 1: Healthy aging research network social ecological model of healthy aging [15].

purpose, environments can be natural or manmade. A major principle of this framework is to emphasize that there are multilevel interventions that can influence healthy behaviors.

For the purposes of this paper, we will focus on the physical environments connected to each level in the model, rather than on such issues as societal norms or behavioral choices. The individual is at the core of this model. He/she is surrounded and influenced by multiple relationships and environmental levels. The closest domain to the individual in this model is the interpersonal environment. It encompasses personal environments or spaces in which individuals should be able to interact effectively with family, friends, and coworkers in such locations as homes and workplaces. The next level is institutional, encompassing an individual's larger neighborhood environment or the spaces in which individuals access needed resources and services, as in grocery stores, neighborhood parks, and healthcare settings. The community level includes community-wide or regional environments or systems in which individuals engage in the larger community and gain access to less regularly needed resources and services. And finally, the public policy domain includes the policies that affect spaces, environments, or systems at all levels, as exemplified by building codes, zoning and land use regulations, and healthcare system policies [16].

\section{Results and Discussion}

3.1. Key Professional Fields. Our paper revealed many and varied professional fields that can influence the social ecological environment to promote safe mobility for successful aging (see Table 1).

Several professions play a key role in multiple domains of our model. We, however, will focus on the most engaged professions, the ones that affect the individual most significantly.

3.2. Professional Roles by Model Domain. The professions and organizations in Table 1 currently have initiatives to influence the environment of aging Americans. We reviewed the current initiatives and have organized them by model domain. 
TABLE 1: Social ecological model for healthy aging domains and their most influential key professions or organizations.

\begin{tabular}{|c|c|c|}
\hline $\begin{array}{l}\text { Social ecological model for } \\
\text { healthy aging: core domain }\end{array}$ & Key professional fields & Representative organizations \\
\hline \multirow{6}{*}{ Interpersonal } & Architects & $\begin{array}{l}\text { American Institute of Architects } \\
\text { (http://www.aia.org/) }\end{array}$ \\
\hline & Building inspectors & $\begin{array}{l}\text { Nat. Academy of Build. Inspect. Engineers } \\
\text { (http://www.nabie.org/) }\end{array}$ \\
\hline & Home builders & $\begin{array}{l}\text { Nat. Association of Home Builders } \\
\text { (http://www.nahb.org/) }\end{array}$ \\
\hline & Housing authorities & $\begin{array}{l}\text { Public Housing Authorities Directors Assoc. } \\
\text { (http://www.phada.org/) } \\
\text { Nat. Council of State Housing Agencies } \\
\text { (http://www.ncsha.org/) Nat. } \\
\text { Assoc. of Housing \& Redevelop. Officials } \\
\text { (http://www.nahro.org/) }\end{array}$ \\
\hline & Injury prevention specialists & $\begin{array}{l}\text { Safe States Alliance } \\
\text { (http://www.safestates.org/) }\end{array}$ \\
\hline & Occupational therapists & $\begin{array}{l}\text { American Occupational Therapy Assoc. } \\
\text { (http://www.aota.org/) }\end{array}$ \\
\hline \multirow{4}{*}{ Institutional } & Gerontology/aging studies & $\begin{array}{l}\text { Gerontological Society of America } \\
\text { (http://www.geron.org/) }\end{array}$ \\
\hline & Housing and community development planner & $\begin{array}{l}\text { American Planning Association } \\
\text { (http://www.planning.org/) }\end{array}$ \\
\hline & Landscape architects & $\begin{array}{l}\text { American Society of Landscape Architects } \\
\text { (http://www.asla.org/) }\end{array}$ \\
\hline & Law enforcement & $\begin{array}{l}\text { International Assoc. of Chiefs of Police } \\
\text { (http://www.theiacp.org/) }\end{array}$ \\
\hline \multirow{6}{*}{ Community } & Aging services specialists & $\begin{array}{l}\text { Nat. Association of Area Agencies on Aging } \\
\text { (http://www.n4a.org/) }\end{array}$ \\
\hline & Healthcare services and facilities administrators & $\begin{array}{l}\text { American Hospital Association } \\
\text { (http://www.aha.org/) }\end{array}$ \\
\hline & Urban and regional planners & $\begin{array}{l}\text { American Planning Association } \\
\text { (http://www.planning.org/) } \\
\text { Assoc. of Metropolitan Planning Organizations } \\
\text { (http://www.ampo.org/) }\end{array}$ \\
\hline & Public health professionals & $\begin{array}{l}\text { Nat. Assoc. of County \& City Health Officials } \\
\text { (http://www.naccho.org/) }\end{array}$ \\
\hline & Parks and recreation specialists & $\begin{array}{l}\text { Nat. Recreation and Park Assoc. } \\
\text { (http://www.nrpa.org/) }\end{array}$ \\
\hline & Transportation/transit planners and engineers & $\begin{array}{l}\text { Institute of Transportation Engineers } \\
\text { (http://www.ite.org/) }\end{array}$ \\
\hline \multirow{3}{*}{ Public Policy } & & $\begin{array}{l}\text { Nat. League of Cities } \\
\text { (http://www.nlc.org/) }\end{array}$ \\
\hline & Policymakers and elected officials & $\begin{array}{l}\text { U. S. Conference of Mayors } \\
\text { (http://www.mayors.org/) }\end{array}$ \\
\hline & & $\begin{array}{l}\text { Nat. Assoc. of Counties } \\
\text { (http://www.naco.org/) }\end{array}$ \\
\hline
\end{tabular}

\subsubsection{Interpersonal/Microlevel Environments} (Interior of Homes, Commercial Facilities, Workplaces, and So Forth)

Architects. The American Institute of Architects (AIA) works to ensure that the built environment meets the reasonable needs of people with disabilities. The AIA focuses on the mission of providing those with a disability, including an age-related disability, the means to participate in society to the extent possible through the elimination of physical barriers in a manner that balances the interests of the physically disabled, the public good, and cost effectiveness [17].

To accomplish this work, AIA calls for its members to adopt ten specific principles for livable communities [18], including

(i) designing in such a way as to create compact, pedestrian-friendly communities that allow residents to walk to shops, services, cultural resources, and 
jobs, thereby reducing traffic congestion and benefiting residents' health;

(ii) providing choices by creating variety in housing, shopping, recreation, transportation, and employment, all to accommodate residents throughout the lifespan;

(iii) creating a variety of transportation options by giving people the option of walking, biking, and using public transit, with the effect of reducing traffic congestion, protecting the environment, and encouraging physical activity.

Architects such as Mace and Maisel et al. have contributed to the pursuit of these goals by creating and implementing such design concepts as universal design [19] and visitability [20]. Universal design calls for the design of products and environments usable by all people to the greatest extent possible, without the need for adaptation or specialized design. Visitability is the use of design and construction practices to ensure that all new homes, not merely those built for those who have disabilities, offer key features that make the home suitable for visitors with impairments and residents who later develop mobility impairments.

Building Inspectors. The National Academy of Building Inspection Engineers encourages its members to adhere to the principles of sustainable development-meeting human needs for food, transportation, and shelter while protecting the environment and its ability to meet the needs of future generations [21]. Members conduct plan review; participate in construction and project design; inspect residential, commercial, and retail buildings. Board-certified building inspection engineers are required to pass a written examination to demonstrate competence in building codes and standards, including compliance with the Americans with Disabilities Act, as well as an ability to ensure the safety and health of building occupants [22].

One specific example of the contribution of building inspectors to improved mobility for older adults is the Homes for Life program in Johnson County, Iowa [23], a voluntary home certification program for new home building and renovation. Homes for Life assures that homes certified by the program will continue to meet occupant needs and be welcoming abodes for visitors for many years. In order to receive certification, applicants must submit construction drawings, including, for instance, a site plan drawn to scale showing an easily navigable route from parking location(s) to an accessible building entrance.

Home Builders. The Fair Housing Amendments Act of 1988 (Fair Housing Act) requires new multifamily buildings constructed for first occupancy after March 13, 1991, and consisting of four or more units to be accessible to disabled persons. In response to the act, the National Association of Home Builders (NAHB) cooperatively developed building code language along with the US Housing and Urban Development (HUD), the International Code Council, and disability advocates. In addition, NAHB policy encourages its members to

(i) actively participate in ongoing education and training efforts to inform builders about accessibility requirements under the Fair Housing Act;

(ii) support adoption of model accessibility building codes endorsed by HUD as providing a safe harbor for complying with the accessibility requirements of the Fair Housing Act;

(iii) work with other interested groups, including building product manufacturers, disability advocates, real estate, and multifamily design and construction groups to promote education, outreach, and compliance with the accessibility requirements of the Fair Housing Act [24].

Reinforcing these organizational policies, NAHB provides support for its membership by (1) helping to create what are known as local 50+ Housing Councils and (2) maintaining what is known as the Aging-in-Place Specialist certification program. The Certified Aging-in-Place Specialist (CAPS) designation program teaches the technical, business management, and customer service skills essential to home modifications for the aging-in-place-including conducting needs assessment to identify and prioritize the needs, wants, and wishes of the aging-in-place client and recommending specific design solutions [25].

Housing Authorities. Housing authorities vary, and they are managed by both elected and appointed staff. The Public Housing Authorities Directors Association, representing a segment of this professional continuum, challenges its members to consider their professional role as an opportunity to serve their communities by providing decent, safe, and sanitary homes and suitable living environments for all citizens, regardless of race, creed, sex, or age [26].

Another segment of this continuum, represented by the National Council of State Housing Agencies, has set itself and its members the goal of protecting, expanding, and increasing the effectiveness of affordable housing programs responsive to the wide range of housing needs-including supportive housing for persons with special needs. Supportive housing achieves the highest level of quality in a number of dimensions, including the following [27].

(i) Physical environment: the design, construction, appearance, physical integrity, and maintenance of the housing units all provide an environment that is attractive, sustainable, functional, appropriate for the surrounding community, and conducive to tenants' stability.

(ii) Access to housing and services: initial and continued access to the housing opportunities and supportive services is not restricted by unnecessary criteria, rules, services requirements, or other barriers.

A final segment of this continuum, represented by the National Association of Housing and Redevelopment Officials, 
has embraced the mission of creating affordable housing and safe, viable communities that enhance the quality of life for all-including meeting the needs of vulnerable populations. The association addresses the living environment of public housing seniors and the disabled by supporting increased resources and by assisting housing authorities in creating state-of-the-art building improvements, including the option of converting housing to assisted living facilities [28].

Injury Prevention Specialists. Injury prevention specialists come from a wide range of professional backgrounds. They include allied health professionals, social workers, therapists, researchers, instructors, and city planners. One professional organization of injury prevention specialists is the Safe States Alliance (SSA), which engages in activities that increase awareness of injury and violence throughout the lifespan as a serious public health problem. The Safe States Alliance (formerly known as the State and Territorial Injury Prevention Directors Association, or STIPDA) embraces several core values, including multidisciplinary collaboration to build a safer America through a culture of inclusion, openness, and accessibility [29]. Among the professional fields vital to Safe States Alliance's efforts are health care services, environmental health, community design, traffic safety, and law enforcement.

SSA has found growing evidence that collaborating with transportation agencies is important, for a strong link exists between transportation policies and the health of communities [30]. In fact, SSA purports that Americans expect their community design to support active transportation, access to public transit and commercial centers, and aging in place. SSA supports such efforts as engineering design changes to roadways, adaptations of vehicles for accessibility, and the provision of alternative transportation options. The organization suggests that communities adopt "Complete Streets" policies [30] to

(i) make streets inclusive and safer for pedestrians and bicyclists;

(ii) require health impact assessments during transportation and land-use planning processes;

(iii) develop transportation and land-use practices that encourage mixed-use communities;

(iv) provide training to community design practitioners to promote land use and infrastructure development that promotes safe mobility throughout the lifespan.

Occupational Therapists. Occupational therapists often play a vital role in helping people develop, maintain, or regain independence through support, training, and resources throughout the lifespan. The main professional organization for occupational therapists is the American Occupational Therapy Association (AOTA). AOTA believes that community mobility in the United States throughout the lifespan is critical for independence, spontaneity, and personal identity. According to AOTA's practice framework, the concept of community mobility includes moving around in the community and using public or private transportation, including driving, or accessing buses, taxi cabs, or other public transportation systems [31].

AOTA members employ a number of tools to support safe mobility for older people. For example, many seniors have a goal of "driving safer longer," and therefore occupational therapists offer education programming, evaluations, and safe driving strategies for those who can still drive safely, while it offers other resources to those for whom safe driving is no longer possible. Additionally, AOTA offers programs to help caregivers provide transportation options for those with special needs, as in the case of people with dementia, and it can provide instruction in wheelchair mobility, accessibility, and environmental modifications when such instruction is necessary.

\subsubsection{Institutional/Intermediate-Level Environments (Exterior Neighborhood Areas)}

Gerontology/Aging Studies. The main professional organization of gerontologists is the Gerontological Society of America (GSA), a multidisciplinary organization [32] that includes medical professionals (physicians, nurses, dentists, pharmacists, and nutritionists), educators, researchers, practitioners, and policymakers. GSA works to foster collaboration among biologists, health professionals, policymakers, and behavioral and social scientists, believing that the intersection of research from diverse areas is the best way to achieve the greatest impact and promote healthy aging.

GSA has created a special interest group focused on physical environments and aging [33]. This group enables the society to promote multidisciplinary research on the relationship between the design of physical environments and successful aging. Additionally, a special interest group formed by GSA focuses on the topic of transportation and aging [33], and one section of the society deals with social research, policy, and practice to enhance collaboration in delivering community-based services, including transportation, nutrition, and housing [34].

Housing and Community Development Planners. For a majority of Americans, housing costs (along with transportation) exceed $50 \%$ of household expenses. The American Planning Association (APA), representing many housing and community development planners, challenges its members to create new models of housing that increase mobility through an emphasis on livability, choice, and access to economic opportunity [35]. The association recognizes that zoning, land-use law, and building codes can all create barriers that make community-based housing for the elderly more difficult to obtain.

Considering alternatives in housing and community development planning can facilitate or even encourage aging-in-place. These alternatives include zoning for accessible dwelling units, creating elder cottage ordinances, and employing various shared living strategies. In some communities, whole developments have been created to tap into such existing entities as universities (called ULRCs or universitylinked retirement communities). Another option is to plan 
for continuing care retirement communities (CCRCs), which provide a range of services and support for community members as they age [36]. CCRC developments, such as John Knox Village in Florida, often include free-standing single-family houses, high-rise condo buildings, and medical facilities with skilled nursing care, so that residents can remain in a community with family and friends as they age and still have access to whatever level of social or medical support they need [37].

Landscape Architects. The vision of the American Society of Landscape Architects (ASLA) is of a world in which the built and natural environments coexist in harmony and sustainable balance, where all peoples can express their diverse heritage and their individual desire to grow and thrive [38]. ASLA believes that

(i) communities are more livable when they strive for social equity and provide places for positive social interaction [39];

(ii) all people should have equal and appropriate physical access to their surroundings through the principles of Universal Design [40];

(iii) design, construction, and management of streets and highways should preferably enhance interconnected transportation options, particularly for pedestrians, bicyclists, transit riders, and people with disabilities [41].

ASLA encourages mixed-use land use that incorporates housing to offer residents the ability to live, learn, work, shop, and play in a healthy, affordable, and walkable setting. ASLA also encourages the development of communities designed to be cohesive and multimodal, with wellconnected, universally accessible transportation systems that provide attractive, safe, comfortable, and cost-effective access to convenient mobility options [41].

Law Enforcement. Law enforcement officials play a key role in ensuring safe and independent mobility for aging Americans. The perception of safety is extremely important to encouraging community mobility. For example, people are less likely to walk and bike in areas where they feel the traffic is too heavy or fast, where roads are too wide to cross safely [42], or where the risk of crime is too great [43].

A professional organization for local police chiefs that has begun to address the issue of neighborhood safety for older people is the International Association of Chiefs of Police (IACP). IACP has recognized the growing elderly population, the unique protection challenges such a population may bring to law enforcement, and the fear of crime and victimization experienced by many older people. In response, IACP has resolved to encourage and promote cooperative, coordinated, and multidisciplinary approaches to address criminal victimization of the elderly [44].

\subsubsection{Community/Macrolevel Environments \\ (Exterior Community-Wide or Regional Areas)}

Aging Services Specialists. Most communities in the United States have resources and services specifically tailored to the needs of their aging population as a means of supporting successful aging. These services are usually specific to a particular need, such as nutrition (nutrition centers, meals on wheels), resource dissemination (local commissions on aging), or transportation (dial-a-ride).

An association that helps link organizations for older people is the National Association of Area Agencies on Aging ( $n 4 a)$. The $\mathrm{n} 4 \mathrm{a}$ recognizes that providing services to seniors must be considered broadly to include multiple sectors and disciplines, including the built environment. Therefore, n4a promotes the concept of livable communities, in which people can live safe, healthy lives throughout the lifespan. The organization believes that public policy must support housing opportunities, transportation systems, and land-use regulations that support active lifestyles, provide access to healthy foods, and encourage social participation as community members age [45]. The organization recommends that communities consider improvements to roadway design, including large-print road signs, dedicated left turn lanes, and extended walk times at pedestrian crosswalks to accommodate older drivers and pedestrians [46].

Healthcare Services and Facilities Administration. Access to healthcare and healthcare facilities is imperative for successful aging. Often, the phrase healthcare accessibility refers only to financial accessibility, but there is a growing body of research indicating that physical access to healthcare services and facilities is also a concern for older Americans. Healthcare services and facilities cannot be physically accessible if buildings are poorly designed so as to make movement in and around them difficult or if equipment is inaccessible, as in the case of equipment or examination tables that do not adjust for people who use wheelchairs [47, 48].

The American Hospital Association (AHA) represents hospitals, allied health networks, their patients, and their communities. AHA has a model aging-in-place initiative [49] that has been adopted by several hospitals in the United States. This initiative strives to keep seniors independent longer by helping them manage their chronic conditions and care while remaining in their homes, rather than in longterm care. According to AHA, this initiative has resulted in improved blood pressure, diet, exercise, and medication compliance for participating community members and has instilled a sense of community support and trust within the community.

Urban and Regional Planners. As previously stated, for a majority of Americans, transportation costs and housing combine to exceed $50 \%$ of household expenses. The American Planning Association (APA) challenges its members to create new models of transportation and metropolitan planning to increase mobility through an emphasis on livability, choice, and access to economic opportunity. APA 
states that US transportation networks must serve all users equitably [35].

According to APA, holistic strategies for community transportation planning can make significant contributions to lowering health care costs and increasing economic output. Increasingly, however, there is a need to think of access in terms of good transit service to connect regions, downtowns, major activity centers, and the people who will work there. Providing direct, safe, and comfortable pedestrian and bicycle facilities can help people of all ages and abilities acquire the knowledge and income they need to be productive members of society [35].

Another organization, the Association of Metropolitan Planning Organizations (AMPO), serves the needs and interests of metropolitan planning organizations (MPOs) nationwide. As a condition for spending federal highway or transit funds in urbanized areas, federal highway and transit statutes require the designation of MPOs, which have responsibility for planning, programming, and coordination of federal highway and transit investments [50].

One example of how planners on a regional level can pursue these mobility-related goals is the Lifelong Communities project in Atlanta, which involves collaboration between the Atlanta MPO, the Atlanta Regional Commission (ARC), and Atlanta's Area Agency on Aging. The Lifelong Communities project focuses on achieving three major goals: promoting housing and transportation options, encouraging healthy lifestyles, and expanding information and access to services. This collaboration has resulted in the creation of ARC Guidelines for Promoting Housing Options for Older Adults through Zoning and in improvements to the Atlanta Region's Coordinated Human Services Transportation Plan [51].

Public Health Professionals. The National Association of County and City Health Officials (NACCHO), representing local health departments (LHDs) across the country, affirms the fundamental role of LHDs in identifying and responding to health inequities. NACCHO addresses the social determinants of health and the barriers to full participation in society. NACCHO supports a holistic approach in public health and disabilities, an approach that considers not only medical health, but also physical, social, emotional, and spiritual health. The organization regards full and meaningful participation in society as an essential ingredient of health. NACCHO advocates for increased research on best practices to create healthy environments, increased societal participation, and improved health and functional status of individuals living with disabilities [52].

A concrete example of public health system actions to address mobility issues in aging is the Maryland Access Point (MAP) of Worcester County, which targets elderly residents and disabled citizens age 18 or over. MAP addresses the need for elderly, vulnerable, and disabled adults to receive consolidated quality care that is efficient and effective in supporting full quality of life. To simplify access to and increased use of appropriate services, three agencies (Worcester County Health Department, Department of Social Services, and Commission on Aging) colocate service delivery efforts at a single site to increase accessibility of services for aging adults in Worcester County. This program is fairly unique in the range of services it provides (including nursing assessment, social support, information and referral, and behavioral health assessment and counseling) and in the colocating of three agencies [53] to provide a range of services.

Parks and Recreation Professionals. Community parks and recreational facilities have long been used throughout the lifespan as social gathering places, as areas where people relax and play, and as locations where people can interact with nature and green space. Parks and recreational facility accessibility in older age can have important public health benefits. These health benefits include increased physical activity that results in reduced rates of heart disease, hypertension, and diabetes; improved psychological wellbeing, such as reduced symptoms of depression and anxiety; increased quality of life from social interactions and access to open space and nature [54].

The National Recreation and Park Association (NRPA) is a nonprofit organization dedicated to the advancement of public parks and recreation opportunities. NRPA has demonstrated its commitment to inclusion of older people by partnering with AARP to organize the AARP/NRPA Walking Program. This is a 10 -week free program intended to promote the benefits of walking for people over the age of 50. It also highlights the benefits of parks and recreation in helping people find safe places to walk, and it provides tools and resources for older people as they choose to get active in their communities [55].

Transportation/Transit Planners and Engineers. Transportation planners and engineers play a crucial role in community mobility. They greatly influence the safe and independent mobility of older people by community design decisions these professionals make on a daily basis. Transportation planners and engineers design the systems and physical environments by which people move around in their communities.

The Institute of Transportation Engineers (ITE) is a professional organization that has a Safety Action Plan. The plan states that the purpose of the organization is to enable transportation engineers, planners, and other professionals with knowledge and competence in transportation and traffic engineering to contribute individually and collectively toward meeting human needs for mobility and safety [56]. ITE recognizes that more people are living longer and that therefore it is important to provide resources, information, and road design consideration for older drivers and pedestrians to reduce the risk of motor vehicle injuries and fatalities.

ITE specifically strives to take the following actions [56]:

(i) identify and promote methods to enhance the driving environment for older road users, including providing traffic control devices, highway geometric features, and illumination;

(ii) promote the Federal Highway Administration (FHWA) Older Driver Handbook and Workshop; 
(iii) promote the application of FHWA's Older Driver Handbook in the design, operation, construction, and maintenance of road facilities.

\subsubsection{Public Policy That Affects All Spatial Levels}

Policymakers and Elected Officials. The National League of Cities (NLC) regards public transportation as an essential public service that provides mobility for all people, including the disabled, elderly, and economically disadvantaged, in all places. To the NLC, public transportation does not exist solely for those who can afford to pay for the service. While recognizing that human resources policy relates to all citizens, NLC supports giving special emphasis and priority to social service funds for the problems of the nation's most vulnerable, including the physically challenged and the elderly. NLC believes that such economic assistance can help people attain their highest level of independent living [57].

Similarly, the U.S. Conference of Mayors (USCM) strongly supports the formulation of a national elderly housing strategy that allows elderly residents to age in place in all forms of subsidized housing. Furthermore, USCM encourages support for programs that bring together shelter, supportive services, healthcare, and social services to help elderly residents remain independent [58].

Finally, the National Association of Counties (NAC) supports a continuum of care for the elderly. The care includes supportive services to assist older persons in remaining active, productive, and independent. These services include appropriate transportation options (including public transit), housing alternatives, and in-home support services [59].

\section{Conclusions}

The aging population in coming years demands that professionals from multiple sectors change their methods of practice to meet the needs of a growing number of seniors. An expanding body of literature highlights the need for a multidisciplinary approach in the planning and service delivery to support successful aging, including safe and independent mobility. Optimal mobility translates into healthy, active lives in which older adults are supported and encouraged to engage in social participation. It is this multidisciplinary approach that will bring a more complete and cohesive practice of mobility-supporting community design.

We have identified several professional fields that play a key role in creating mobility-supporting environments for the aging population. It is essential that these professionals pursue and value collaborations with other key players. Professionals interested in such collaborations have many tools and models available for creating environments that support successful aging. One such tool is the Prevention Institute's Spectrum of Prevention [60]. The Spectrum of Prevention is a systematic tool that identifies multiple levels of intervention and helps professionals develop collaborative relationships and strategies to effect change. It has been used nationally in prevention initiatives targeting traffic safety, violence prevention, injury prevention, nutrition, and fitness. A related tool often used with the Spectrum of Prevention is the Collaboration Multiplier, in which collaborative groups "add" to each other's information pool, "average" definitions by agreeing to a common language, "multiply" capacity through training, and "divide" up responsibility for the overall work [61]. This collaboration math typically plays out as dialogue among groups about how they, collectively, can make best use of their diverse backgrounds and resources. The benefits of collaboration grow exponentially as more professionals are added and more projects explored.

The Institute of Medicine (IOM) points out that the "public [health] sector at the community level encompasses local government officials and agencies traditionally seen as having health-related responsibilities, as well as many others that have important but sometimes less obvious roles in health but whose policies and objectives may have potential health consequences...includ[ing] city councils, public schools, colleges and universities, police and fire departments, zoning boards, housing authorities, parks and recreation agencies" [62]. By teaming with other disciplines and fields, groups can use their time and effort to achieve maximum results in creating mobility-supporting communities. For example, when public health, transportation engineering, optometry, community planners, and law enforcement work together, traffic safety can be maximized by

(i) identifying at-risk individuals (public health);

(ii) making roads and sidewalks safer (transportation engineering);

(iii) providing guidance on traffic sign/signal visibility (optometry);

(iv) creating infrastructure that minimizes encounters between pedestrians and motor vehicles (community planning);

(v) enforcing speed limits (law enforcement).

The result is a safer, more supportive mobility environment.

As the implications of these evolving concepts have become clear, a consensus has developed that the responsibilities for health promotion are not just those of the traditional health sector; rather, the responsibilities rest in the hands of many nontraditional actors as well. It is this dynamic that, in part, motivated the IOM to define public health as "what we, as a society, do collectively [emphasis added] to assure the conditions in which people can be healthy" [62]. This aspirational definition places the responsibility for health promotion not only on the individual but also on society as a whole.

\section{Disclaimer}

The findings and conclusions in this paper are those of the author(s) and do not necessarily represent the views of the Centers for Disease Control and Prevention. 


\section{References}

[1] Federal Interagency Forum on Aging-Related Statistics, "Older Americans 2010: key indicators of well-being," Hyattsville, Md, USA, http://www.agingstats.gov/agingstatsdotnet/Main_ Site/Data/2010_Documents/Docs/OA_2010.pdf.

[2] Y. Gorina and H. Lentzner, "Multiple causes of death in old age," Aging Trends, no. 9, pp. 1-9, 2008.

[3] C. F. Dillon, Q. Gu, H. J. Hoffman, and C. W. Ko, "Vision, hearing, balance, and sensory impairment in Americans aged 70 years and over: United States, 1999-2006," NCHS Data Brief, no. 31, pp. 1-8, 2010.

[4] Administration on Aging, "A profile of older americans: 2009, disability and activity limitations," http://www.aoa.gov/ AoARoot/Aging_Statistics/Profile/2009/16.aspx.

[5] R. H. Lawrence, S. L. Tennstedt, L. E. Kasten, J. Shih, J. Howland, and A. M. Jette, "Intensity and correlates of fear of falling and hurting oneself in the next year: baseline findings from a roybal center fear of falling intervention," Journal of Aging and Health, vol. 10, no. 3, pp. 267-286, 1998.

[6] B. J. Vellas, S. J. Wayne, L. J. Romero, R. N. Baumgartner, and P. J. Garry, "Fear of falling and restriction of mobility in elderly fallers," Age and Ageing, vol. 26, no. 3, pp. 189-193, 1997.

[7] G. Hendershot, "Community participation and life satisfaction," 2003, www.nod.org/index.cfm?fuseaction=Feature .showFeature\&FeatureID $=1129$.

[8] J. Lynott, B. McCann, E. Stollof et al., "Planning complete streets for an aging america," 2009, http://mayoresearch.mayo .edu/aging_center/aging_demographics.cfm.

[9] Mayo Clinic Robert and Arlene Kogod Center on AgingAging Demographics, ttp://mayoresearch.mayo.edu/aging center/aging_demographics.cfm.

[10] "White House Conference on Aging, 2005. The booming dynamics of aging: from awareness to action ," 2005, http://www.whcoa.gov/Final_Report_June_14nowater.pdf.

[11] CDC Prevention Research Centers Healthy Aging Research Network. Logic Model Narrative, 2005, http://www.prc-han .org/docs/logicmodnarrative.pdf.

[12] World Health Organization, 2002. Towards a Common Language for Functioning, Disability and Health: The International Classification of Functioning, Disability and Health (ICF), http://www.who.int/classifications/icf/training/ icfbeginnersguide.pdf.

[13] EPC Clearinghouse: Searchable Database of Environmental and Policy Change Resources, http://depts.washington.edu/ hansite/drupal/?t=1288667091814.

[14] Centers for Disease Control and Prevention, National Center for Environmental Health, Healthy Places Website, Additional Resources, 2010, http://www.cdc.gov/healthyplaces/resources .htm.

[15] Healthy Aging Research Network Social Ecologic Model of Healthy Aging (Modified from sources: McLeroy et al., 1988, Health Educ Q; Sallis et al., 1998, American Journal of Preventive Medicine), http://www.prc-han.org/docs/semodel.pdf.

[16] J. F. Sallis, A. Bauman, and M. Pratt, "Environmental and policy interventions to promote physical activity," American Journal of Preventive Medicine, vol. 15, no. 4, pp. 379-397, 1998.

[17] American Institute of Architects, 2006. Blueprint for America, http://www.aia150.org/files/bl150_criteria_0106.pdf.

[18] American Institute of Architects. AIA Communities by Design's 10 Principles for Livable Communities, http://www .aia.org/about/initiatives/AIAS075369.
[19] R. Mace, The Center for Universal Design. North Carolina State University, 1997, http://www.ncsu.edu/ncsu/design/cud/ about_ud/about_ud.htm.

[20] J. Maisel, E. Smith, and E. Steineld, "Increasing home access: designing for visitability. AARP public policy institute," 2008, http://assets.aarp.org/rgcenter/il/2008_14_access.pdf.

[21] National Society of Professional Engineers, "NSPE code of ethics for engineers," 2010, http://www.nspe.org/Ethics/ CodeofEthics/index.html.

[22] National Academy of Building Inspection Engineers, "Certification Program Guidelines," 2007, http://www.nabie.org/ certprogram.html.

[23] Homes for Life: A Voluntary Universal Design Certification Program, 2008. (Johnson County Livable Community for Successful Aging Initiative and the Greater Iowa City Area Home Builders Association), http://www.icgov.org/site/ CMSv2/file/housing/HomesforLife.pdf.

[24] National Association of Home Builders, 2009. Policy on Accessibility Requirements for Fair Housing, http://www.huduser .org/publications/pdf/fairhousing/fairappa.pdf.

[25] Description of the NAHB Certified Aging-In-Place Specialist (CAPS) program 2011, http://www.nahb.org/page.aspx/ category/sectionID=686.

[26] "Code of professional ethics for housing authority commissioners," Public Housing Authorities Directors Association, http://www.phada.org/coecom.pdf.

[27] CSH-NCSHA e-Manual for Supportive Housing Funders: A Guide to Tools and Resources for State Housing Finance Agencies and Other Public Funders of Supportive Housing (developed jointly by the Corporation for Supportive Housing and the National Council of State Housing Agencies 2008, http://documents.csh.org/documents/eManualFunders/CSH_ NCSHAeManualforFunders.pdf.

[28] NAHRO Policy Position on Elderly and Disabled. National Association of Housing and Redevelopment Officials, http:// 208.112.78.36/programs/other/elderly/index.cfm.

[29] Safe States Alliance Mission Statement, http://www.safestates .org/displaycommon.cfm?an=1.

[30] Issue Brief: Effective Transportation Policies Require Injury Prevention Strategies. State \& Territorial Injury Prevention Directors Association 2009, http://www.safestates.org/ associations/5805/files/IVP\%20and\%20Transportation $\% 20$ Policy\%20-\%20STIPDA\%202009.pdf.

[31] American Occupational Therapy Association, "Occupational therapy practice framework: domain and process," American Journal of Occupational Therapy, vol. 56, pp. 609-639, 2002.

[32] Gerontological Society of America Mission Statement, http:// www.geron.org/About\%20Us/Our\%20Mission.

[33] Gerontological Society of America. List of Formal Interest Groups, http://www.geron.org/Resources/Interest\%20Groups/ formal-interest-groups\#physical.

[34] Gerontological Society of America. Social Research, Policy, Practice Section Website, http://www.geron.org/Membership/ Sections/Social\%20Research,\%20Policy\%20\&\%20Practice? Practice.

[35] American Planning Association. Policy Guide on Surface Transportation (2010), http://www.planning.org/policy/ guides/adopted/surfacetransportation.htm.

[36] T. Rosen, “Grey Matters,” Duke Magazine, vol. 92, no. 6, 2006.

[37] John Knox Village, http://www.johnknoxvillage.com/homestyles/home-styles-overview/.

[38] American Society of Landscape Architects Leadership Handbook, 2010, http://www.asla.org/Leadershiphandbook.aspx? id=3766\&ItemIdString=eeb11f839_34_116_3766. 
[39] ASLA Professional Practice Resource Center, "Livable communities guide," 2010, http://www.asla.org/contentdetail.aspx? id $=23888$.

[40] ASLA Policy Statement on Universal Design, 2001, http://www .asla.org/WorkArea/DownloadAsset.aspx?id=3696.

[41] ASLA Policy Statement on Livable Communities, 2008, http:// www.asla.org/WorkArea/DownloadAsset.aspx?id=3660.

[42] US Environmental Protection Agency, Aging Initiative. Growing smarter, living healthier: A guide to smart growth and active aging. EPA 100-K-09012, August 2009.

[43] C. R. Clark, I. Kawachi, L. Ryan, K. Ertel, M. E. Fay, and L. F. Berkman, "Perceived neighborhood safety and incident mobility disability among elders: The hazards of poverty," BMC Public Health, vol. 9, article no. 162, 2009.

[44] International Association of Chiefs of Police, Crime Prevention: Support of actively eliminating criminal victimization of the elderly, http://www.iacp.org/resolution/ index.cfm?fa=dis_public_view\&resolution_id=297\&CFID= 66844068\&CFTOKEN=12291186.

[45] Partners for Livable Communities and National Association of Area Agencies on Aging, "A Blueprint for action: developing livable communities for all ages," http://www.n4a.org/pdf/07116-N4A-Blueprint4ActionWCovers.pdf.

[46] The National Association of Agencies on Aging, "The maturing of america: getting communities on track for an aging population,” 2006, http://www.n4a.org/files/programs/ livable-communities/maturing-of-america.pdf.

[47] L. I. Iezzoni and B. R. O'Day, More than Ramps: A Guide to Improving Health Care Quality and Access for People with Disabilities, Oxford Press, New York, NY, USA, 2006.

[48] Institute of Medicine (IOM), The Future of Disability in America, The National Academics Press, Washington, DC, USA, 2007.

[49] American Hospital Association, http://www.aha.org/aha/ about/index.html.

[50] Association of Metropolitan Planning Organizations, http:// www.ampo.org/what/index.php.

[51] Atlanta Regional Commission Lifelong Communities, 2010, http://www.atlantaregional.com/aging-resources/lifelongcommunities-llc.

[52] NACCHO Policy Statement on Health and Disability, http:// www.naccho.org/advocacy/positions/upload/08-02Healthand-Disability.pdf.

[53] NACCHO Model Practices Database: Maryland Access Point of Worcester County, http://www.naccho.org/topics/ modelpractices/database/practice.cfm?practiceID $=414$.

[54] The Trust for Public Land, The Benefits of Parks: Why American needs more city parks and open space, 2006.

[55] National Recreation and Parks Association, AARP Walking Program, http://www.nrpa.org/aarp/.

[56] "Institute of Transportation Engineers Safety Action Plan," 2000, http://www.ite.org/pdf/safeactplan.pdf.

[57] National League of Cities, "Transportation Infrastructure and Services Principles and Policies," 2009, http://www.nlc.org/ influence-federal-policy/policy-committees/transportationinfrastructure-services.

[58] U.S. Conference of Mayors Community Development and Housing Policy: Housing for the Elderly, 1999, http:// www.usmayors.org/resolutions/67th_conference/housing housing.htm.

[59] National Association of Counties Human Services and Education Policy Resolutions, 2010, http://www.naco.org/ legislation/policies/Documents/Human\%20Services/HSE \%2010-11\%20Platform\%20and\%20Resolutions.pdf.
[60] Spectrum of Prevention, Prevention Institute, http://www .preventioninstitute.org/component/taxonomy/term/list/94/ 127.html.

[61] Collaboration Multiplier, Prevention Institute, http://www .preventioninstitute.org/component/jlibrary/article/id-44/ 127.html.

[62] Institute of Medicine, The future of the public's health in the 21st century, National Academies Press, Washington, DC, USA, 2002. 


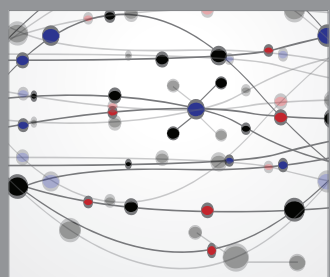

The Scientific World Journal
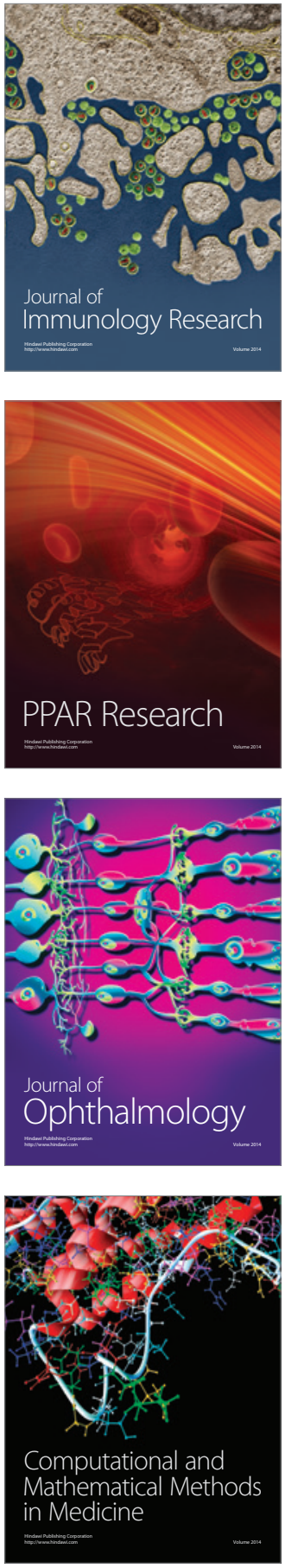

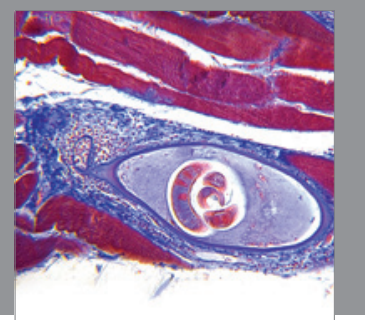

Gastroenterology

Research and Practice
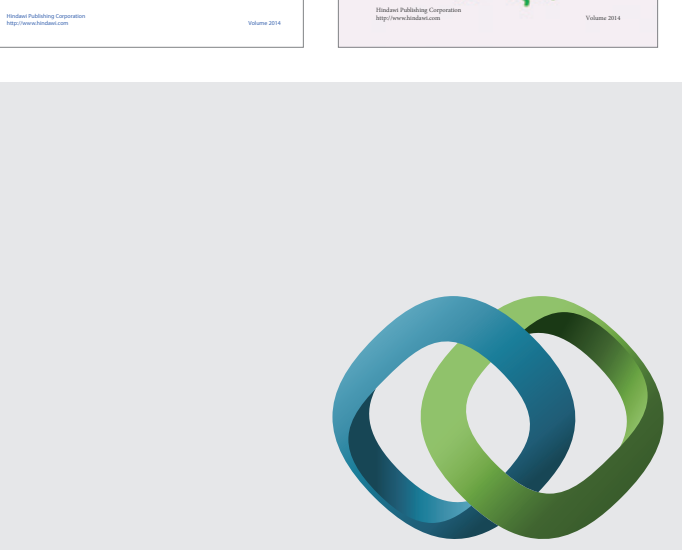

\section{Hindawi}

Submit your manuscripts at

http://www.hindawi.com
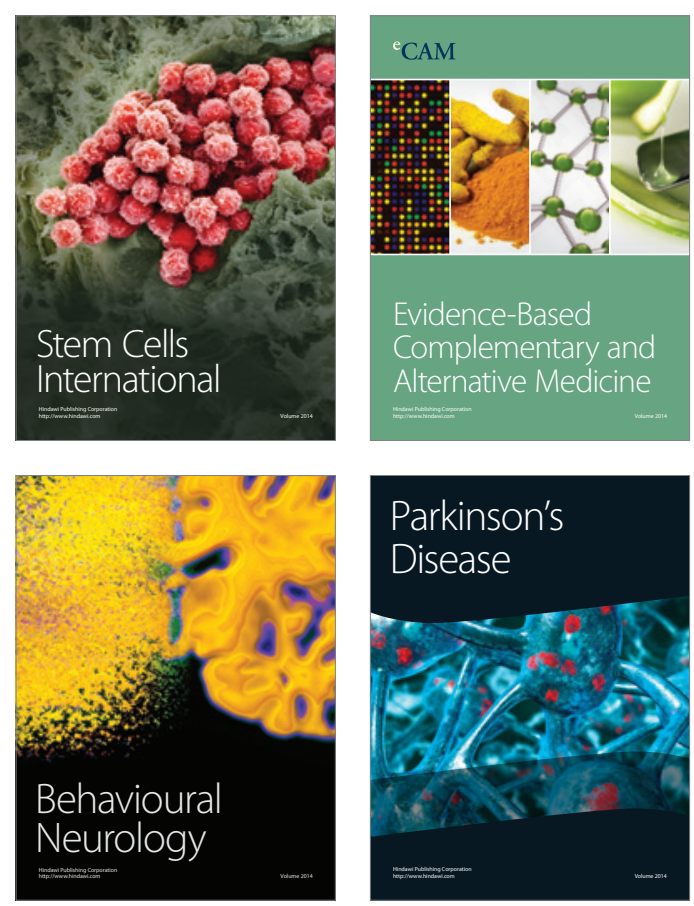

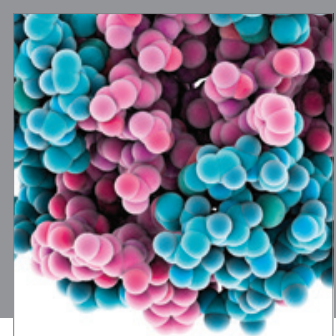

Journal of
Diabetes Research

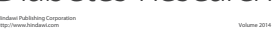

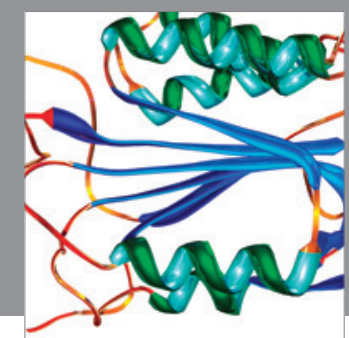

Disease Markers
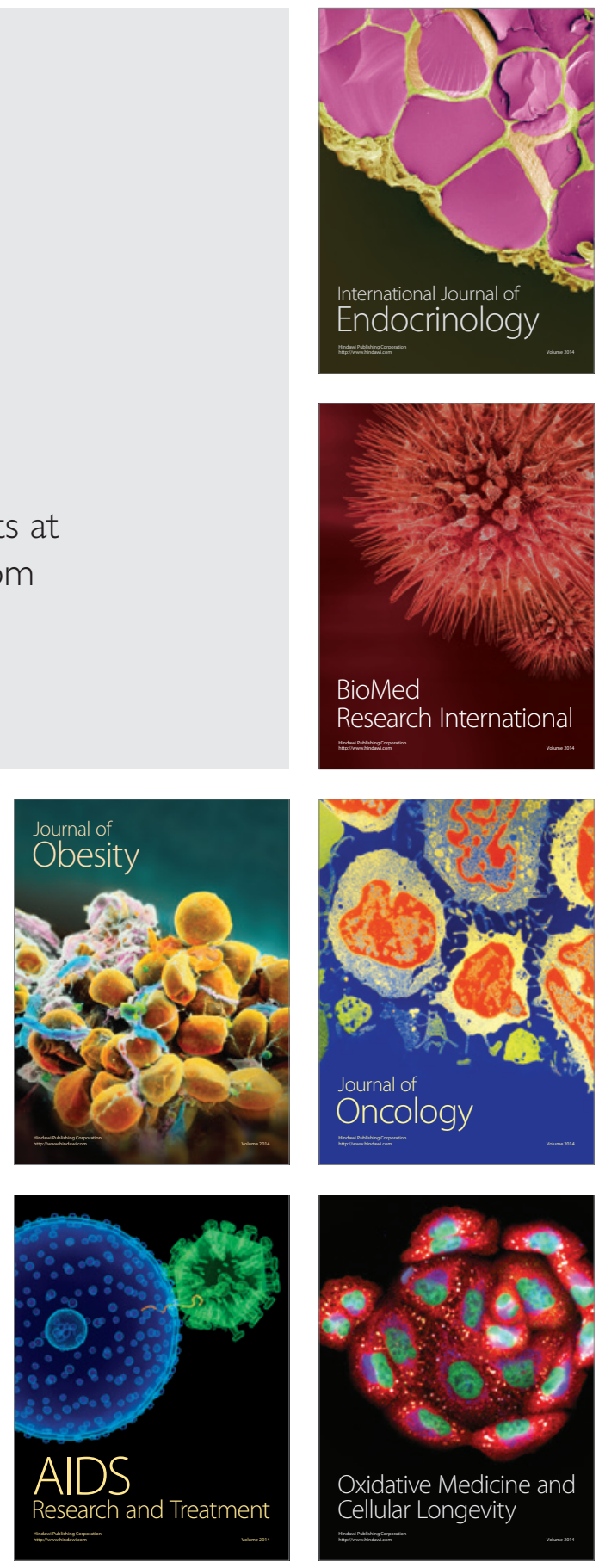